\title{
Synthesis of $\mathrm{SiO}_{2}-\mathrm{TiO}_{2}$ fibers with photocatalytic activity by $\mathrm{TiCl}_{4}$ vapor curing on melt-spun silicone resin fiber
}

\author{
Masaki NARISAWA ${ }^{\dagger}$ Yayoi SATOH, Takashi KAMEGAWA* and Hiromi YAMASHITA* \\ Department of Materials Science, Graduate School of Engineering, Osaka Prefecture University, \\ 1-1 Gakuen-cho, Naka-ku, Sakai, Osaka 599-8531 \\ *Division of Materials and Manufacturing Science, Graduate School of Engineering, Osaka University, \\ 2-1 Yamadaoka, Suita, Osaka 565-0871
}

\begin{abstract}
Melt spun silicone resin fiber with a diameter of $14 \mu \mathrm{m}$ was exposed to $\mathbf{T i C l}_{4}$ vapor with flowing nitrogen at room temperature or $40^{\circ} \mathrm{C}$. During the exposure, $\mathrm{TiCl}_{4}$ was incorporated in the resin network with formation of cross-links. After standing in ambience for $24 \mathrm{~h}$ and pyrolysis in an air flow, $\mathrm{SiO}_{2}-\mathrm{TiO}_{2}$ fibers were obtained in a yield of $75-80 \%$. Ti/Si content can be controlled by adjusting the curing time and temperature. $\mathrm{TiO}_{2}$ existed as nano particles or aggregated large particles, which were strongly attached on the fiber body. Analysis of 2-propanol degradation by the fiber under UV light suggested the existence of photocatalytic activity.
\end{abstract}

(C2011 The Ceramic Society of Japan. All rights reserved.

Key-words : Precursor method, Silicone resin, $\mathrm{SiO}_{2}-\mathrm{TiO}_{2}$, Fiber, Photocatalytic activity

[Received March 22, 2011; Accepted April 14, 2011]

\section{Introduction}

Photocatalytic activity of $\mathrm{TiO}_{2}$ attracts great interest because of their efficiency for decomposition of various environmental pollutions, mainly organic materials including chlorides, nitrides and sulfur. ${ }^{1)-3)}$ Even bacillus bio pollution accepts the $\mathrm{TiO}_{2}$ effects. The $\mathrm{TiO}_{2}$ was activated by UV light and oxygen species, like $\mathrm{O}^{2}-$ and $\mathrm{OH}$ radicals, were formed on the surface. ${ }^{4)}$ For common uses, the $\mathrm{TiO}_{2}$ was applied on the surface of some substrates as coating layers. ${ }^{5)-7)}$ In 2002, Ishikawa et al. in UBE industry developed the unique process for $\mathrm{TiO}_{2}$ application on thin silica fibers. ${ }^{8)}$ In their process, Ti compound with low molecular weight was added in polycarbosilane (PCS). After the melt spinning and low temperature heat treatment, Ti compound was bloomed out on surface area, which was converted to anatase $\mathrm{TiO}_{2}-\mathrm{SiO}_{2}$ layer by pyrolysis in air. ${ }^{9), 10)}$ Tailored gradient structure contributed strong attachment of the layer to the silica core. The fiber bundle possessed relatively high surface area, and the tailored layer can resist shear stress caused by fluid. It is now used in commercialized water purification system, which maintains efficiency even in hot environment.

Such synthesis process based on the PCS nature is, however, difficult and not common. The polymer, PCS, is not popular in a large industrial scale as compared with conventional polymers. Cost of the PCS is also high. Here, we propose another handy and easy process for making $\mathrm{SiO}_{2}-\mathrm{TiO}_{2}$ fiber by using a commercialized silicone resin and titanium tetrachloride $\left(\mathrm{TiCl}_{4}\right)$. The used silicone resin consists of the structure unit of $-\mathrm{Si}\left(\mathrm{CH}_{3}\right) \mathrm{O}_{1.5^{-}}$with whole chemical composition of $\mathrm{SiC}_{1.22} \mathrm{O}_{1.78} \mathrm{H}_{3.67}$. Such "ladder-type" methyl silicones can be easily shaped to porous bodies, particles, thick coatings, and fibers by controlling the melting, dissolution and cross-linking processes. ${ }^{11-13)}$ In previous study, we reported that silicone resin

$\dagger$ Corresponding author: M. Narisawa; E-mail: nar@mtr.osakafu-u. ac.jp fiber showed interaction with metal chloride vapors and formed cross-links, which were effective to maintain fiber shape during pyrolysis. ${ }^{14), 15)}$ In this study, we report the systematic study for synthesizing $\mathrm{SiO}_{2}-\mathrm{TiO}_{2}$ fibers with controlled $\mathrm{Ti} / \mathrm{Si}$ content by adjusting the curing conditions.

\section{Experimental procedure}

The silicone resin fiber with an averaged diameter of $14 \mu \mathrm{m}$ was obtained by melt spinning of YR 3370 (Momentive Preformance Materials Japan, $\mathrm{SiC}_{1.22} \mathrm{O}_{1.78} \mathrm{H}_{3.67}$ ) at $150^{\circ} \mathrm{C}$ by using an $\mathrm{Ar}$ gas pressure. Detailed conditions of the fiber spinning were described in a previous article. ${ }^{14)} \mathrm{TiCl}_{4}$ incorporation in the resin fiber was performed in a tube type flow system. $100 \mathrm{mg}$ of the fiber bundle and $5 \mathrm{ml}$ of $\mathrm{TiCl}_{4}$ in a glass dish was put in the glass tube in an inner diameter of $70 \mathrm{~mm}$. The distance between the bundle and $\mathrm{TiCl}_{4}$ was settled at $70 \mathrm{~mm}$. Under flowing nitrogen from the dish to the bundle in a rate of $50 \mathrm{ml} / \mathrm{min}$, the system was held for 6-24 h at room temperature. $4 \mathrm{~h}$ treatment at $40^{\circ} \mathrm{C}$ by using a rubber heater was also performed to promote a large amount of the $\mathrm{TiCl}_{4}$ incorporation. All the glassware was pre-heat treated in an oven, and an end of the tube was covered by a glove bag purged with nitrogen during treatment of $\mathrm{TiCl}_{4}$ in order to avoid moisture.

Cured fibers was pyrolyzed in an air flow of $300 \mathrm{ml} / \mathrm{min}$ up to $1000^{\circ} \mathrm{C}$ with a heating rate of $200^{\circ} \mathrm{C} / \mathrm{h}$. Ti/Si ratios in the obtained fibers was analyzed by ICP-AES (Optima 4300 DV, Perkin Elmer). Morphology of the fiber was observed by FESEM (S-4500, Hitachi). XRD patterns were obtained by X-ray diffractometer (RINT-1100, Rigaku).

For the evaluation of photocatalytic activity, $50 \mathrm{mg}$ of the $\mathrm{SiO}_{2}-\mathrm{TiO}_{2}$ fiber was immersed in $25 \mathrm{ml}$ of 2-propanol aqueous solution $\left(2.16 \times 10^{-4} \mathrm{~mol} / \mathrm{l}\right)$. After $30 \mathrm{~min}$ of $\mathrm{O}_{2}$ bubbling, UV light (High pressure $\mathrm{Hg}$ lamp, $5.0 \mathrm{~mW} / \mathrm{cm}^{2}$ at $360 \mathrm{~nm}$ ) was irradiated on the fiber. Decreasing rate of 2-propanol was monitored by a gas chromatograph (Shimazu GC-14B) equipped with a Porapak Q column. 

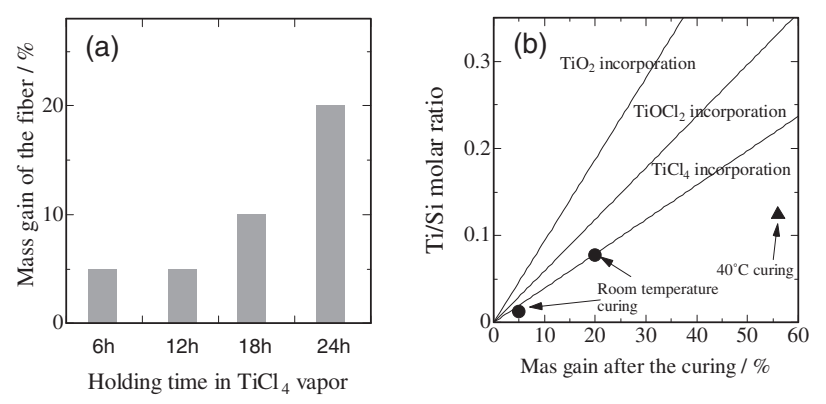

Fig. 1. Relationship between $\mathrm{Ti} / \mathrm{Si}$ ratios in resulting fibers and mass gains during $\mathrm{TiCl}_{4}$ curing; (a) Mass gains during the curing, (b) analyzed $\mathrm{Ti} / \mathrm{Si}$ ratios in the fibers.

\section{Results and discussion}

Figure 1(a) shows mass gains of the fiber during the curing process at room temperature. As the curing time goes on, the mass of the fiber increases. After standing for $24 \mathrm{~h}$, the mass gain reaches to $20 \%$. On the other hand, the exposure at $40^{\circ} \mathrm{C}$ for $4 \mathrm{~h}$ causes $56 \%$ mass gain on the fiber, which is far higher than the obtained mass gains at room temperature. After the pyrolysis of the cured fibers at $1273 \mathrm{~K}$, the $\mathrm{SiO}_{2}-\mathrm{TiO}_{2}$ fibers are obtained in the yield of $75-80$ mass $\%$. The fibers are not fused and hold their shape during pyrolysis. The resulting $\mathrm{Ti} / \mathrm{Si}$ molar ratios in the $\mathrm{SiO}_{2}-\mathrm{TiO}_{2}$ fibers analyzed by ICP-AES are plotted against mass gains during the curing [Fig. 1(b)]. The $\mathrm{Ti} / \mathrm{Si}$ ratios in the fiber cured at room temperature are consistent with a linear line calculated on the basis of $\mathrm{TiCl}_{4}$ capturing. In the case of the $40^{\circ} \mathrm{C}$ curing, however, the obtained $\mathrm{Ti} / \mathrm{Si}$ content is only a half of the calculated value. It suggests partial removal of Ti compounds from the fiber during the pyrolysis. Since the fiber shape was maintained during the pyrolysis, reaction of $\mathrm{TiCl}_{4}$ with $\mathrm{Si}-\mathrm{OH}$ was suggested. The main $\mathrm{Ti}$ components, however, deeply penetrated in the fiber with holding $\mathrm{TiCl}_{4}$ composition. In particular, the fiber was swelled by a large amount of $\mathrm{TiCl}_{4}$ at $40^{\circ} \mathrm{C}$, because of loose network nature.

Figure 2 shows the XRD patterns of the $\mathrm{SiO}_{2}-\mathrm{TiO}_{2}$ fibers derived from the fiber with $20 \%$ mass gain (room temperature) and $56 \%$ mass gain $\left(40^{\circ} \mathrm{C}\right)$. In the fiber with $20 \%$ mass gain, major rutile phase of $\mathrm{TiO}_{2}$ overlaps on amorphous silica patterns. In this case, $\mathrm{TiCl}_{4}$ was trapped in the resin fiber and effectively converted to rutile by direct oxidation during the pyrolysis.

$$
\begin{aligned}
& \mathrm{TiCl}_{4}+\mathrm{O}_{2} \rightarrow \mathrm{TiO}_{2}+2 \mathrm{Cl}_{2} \\
& 1 / 2 \mathrm{Cl}_{2}+\mathrm{CH}_{3}-\rightarrow \mathrm{HCl}+\bullet \mathrm{CH}_{2}-
\end{aligned}
$$

Removed chloride from $\mathrm{TiCl}_{4}$ reacted with organic groups in the resin and yielded $\mathrm{HCl}$ as a gaseous product. Anyway, direct evolution of chlorine gas is minor, because the resin contains a large amount of hydrogen. In the case of polyvinylchloride (PVC) decomposition, removal of $\mathrm{HCl}$ from side groups proceeds simultaneously with forming residual double bonds on main chains. ${ }^{16)}$ It is probable also in the $\mathrm{TiCl}_{4}$ cured resin fibers that the decomposition of $\mathrm{TiCl}_{4}$ [Eq. (1)] and evolution of $\mathrm{HCl}$ [Eq. (2)] proceeds simultaneously, because polymer degradation process is often accompanied by formation and hopping of hydrogen radicals, which is possible source of $\mathrm{HCl}$. The characterization of the intermediate state of the degradation of $\mathrm{TiCl}_{4}$-cured resin fiber is, however, future issue at present.

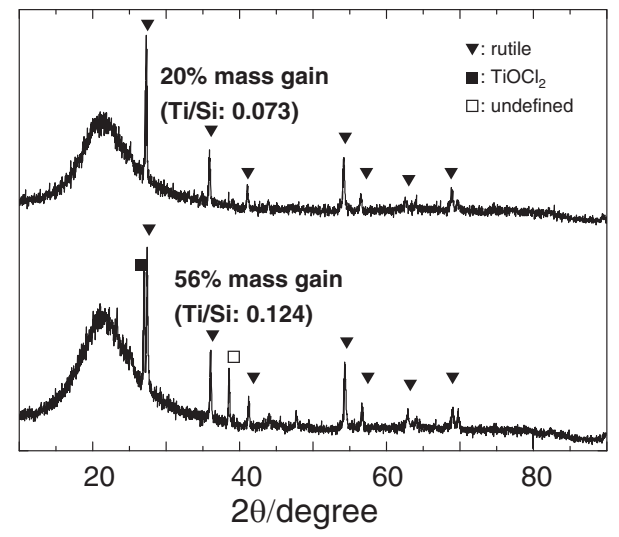

Fig. 2. $\mathrm{XRD}$ patterns of the $\mathrm{SiO}_{2}-\mathrm{TiO}_{2}$ fibers pyrolyzed at $1000^{\circ} \mathrm{C}$.
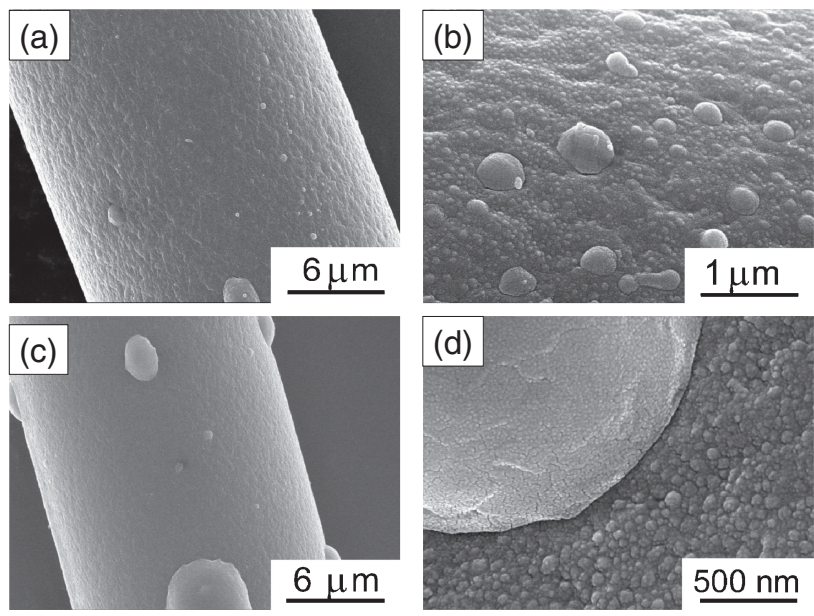

Fig. 3. $\mathrm{SEM}$ images of the $\mathrm{SiO}_{2}-\mathrm{TiO}_{2}$ fibers cured at room temperature; (a), (b) fiber with $6 \mathrm{~h}$ curing (Ti/Si: 0.013) (c), (d) fiber with $24 \mathrm{~h}$ curing (Ti/Si: 0.078).

In the case of $56 \%$ mass gain, however, conversion of $\mathrm{TiCl}_{4}$ to $\mathrm{TiO}_{2}$ does not proceed completely. The XRD patterns of the fibers contain a sharp peak of $\mathrm{TiOCl}_{2}$ with rutile and amorphous silica. These results also suggest the existence of excess $\mathrm{TiCl}_{4}$ in the network. On the other hand, assignment of a sharp peak at $38^{\circ}$ is ambiguous at present. The position is consistent with a diffraction of minor phase of titanium. The fiber obtained after pyrolysis is, however, colored white.

Figure 3 shows $\mathrm{SEM}$ images of the $\mathrm{SiO}_{2}-\mathrm{TiO}_{2}$ fibers derived from the cured resin fibers with 5\% mass gain and $20 \%$ mass gain. In spite of different $\mathrm{Ti}$ content, the surface of the fiber shows almost similar structure. The fiber surface is wholly covered by small grains in the size of $20-100 \mathrm{~nm}$. On the other hand, large grains in the size of $1-2 \mu \mathrm{m}$ are sometimes observed on the fiber surface. All the large grains are strongly attached on the fiber and no independent grains apart from the surface are observed. As the heating rate of the fiber pyrolysis increases, the number of such large grains tends to increase. Origin of such large grains may be liquid $\mathrm{TiCl}_{4}$ partly sweated out from the resin network.

On the other hand, Fig. 4 shows SEM images of the $\mathrm{SiO}_{2}-$ $\mathrm{TiO}_{2}$ fiber derived from the cured fiber with $56 \%$ mass gain. The size of the grains on the fiber is relatively large and the fiber surface is often wrinkled. The most characteristic morphology of these fibers is long cracks along the fiber axis. Perhaps, fiber 

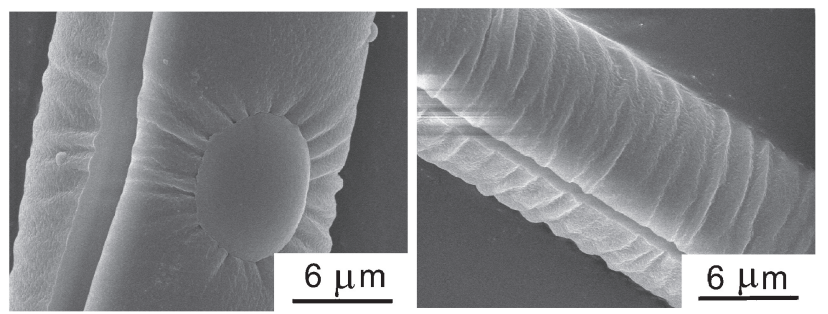

Fig. 4. SEM images of the $\mathrm{SiO}_{2}-\mathrm{TiO}_{2}$ fibers cured at $40^{\circ} \mathrm{C}$ for $4 \mathrm{~h}$ (Ti/Si: 0.123 ).

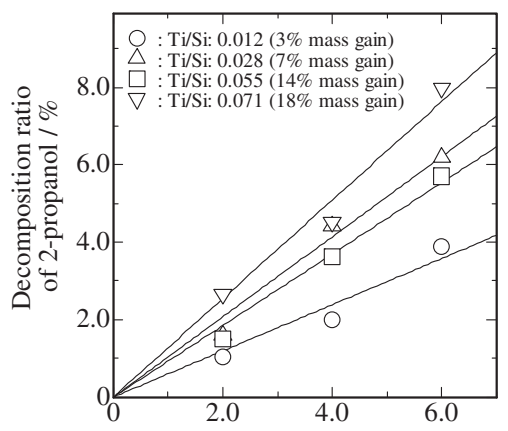

$\mathrm{UV}$ irradiation time / $\mathrm{h}$

Fig. 5. Analysis of photocatalytic activity of $\mathrm{SiO}_{2}-\mathrm{TiO}_{2}$ fibers.

surface can not resist $\mathrm{HCl}$ gas pressure at such high $\mathrm{TiCl}_{4}$ content, and cracks are formed during the pyrolysis. Part of the $\mathrm{TiCl}_{4}$ removal from the opened cracks is also suggested, because the final $\mathrm{Ti}$ content in the fiber is lower than the predicted line.

Figure 5 shows the analysis results of photocatalytic activity of the synthesized fibers. ${ }^{17), 18)}$ Even the fiber with the $3 \%$ mass gain by $\mathrm{TiCl}_{4}$ incorporation shows photocatalytic activity on 2-propanol decomposition. The increase in $\mathrm{Ti} / \mathrm{Si}$ content, however, does not guarantee the linear increase of the photocatalytic activity. At high $\mathrm{Ti} / \mathrm{Si}$ content, the efficiency of $\mathrm{Ti}$ incorporation in the fiber is saturated.

As compared with the commercialized $\mathrm{TiO}_{2}$ powders ( $\mathrm{P}-25$, specific surface area of $50 \mathrm{~m}^{2} / \mathrm{g}$ ), the estimated photocatalytic activity of the fiber corresponds to $1 / 60-1 / 100$ of that of P-25. One of the reasons of such low activity is a small surface area of the fiber as compared with tiny particles. Another reason is probably absence of anatase in the synthesized fibers, which is known to be more effective as a photocatalyst. ${ }^{19)}$

In order to accelerate the anatase formation, we elongated the standing time of the fiber from 1 day to 2 weeks to promote the surface hydrolysis by ambient moisture. Figure 6 shows an expanded XRD pattern of the $\mathrm{SiO}_{2}-\mathrm{TiO}_{2}$ fiber after the elongated hydrolysis and pyrolysis. A small peak of anatase is observed besides a large peak of rutile. Perhaps, such anatase phase originated from $\mathrm{Ti}-\mathrm{O}-\mathrm{Ti}$ network trapped in the resin network. Anatase is low temperature stable phase in general, and rapid growth of $\mathrm{TiO}_{2}$ crystals is suggested to be inhibited in interpenetrated structure between cross-linked resin and $\mathrm{Ti}-\mathrm{O}-\mathrm{Ti}$ networks. In a case of a sol-gel method, incorporation of silica in titania was reported to be effective to reduce the structure evolution during heat treatment. ${ }^{20)}$ Even with such elongated hydrolysis, however, anatase is minor species. Since interaction between $\mathrm{TiCl}_{4}$ and the resin is high, $\mathrm{TiCl}_{4}$ once trapped into the deep area of the fiber does not accept the hydrolysis easily.

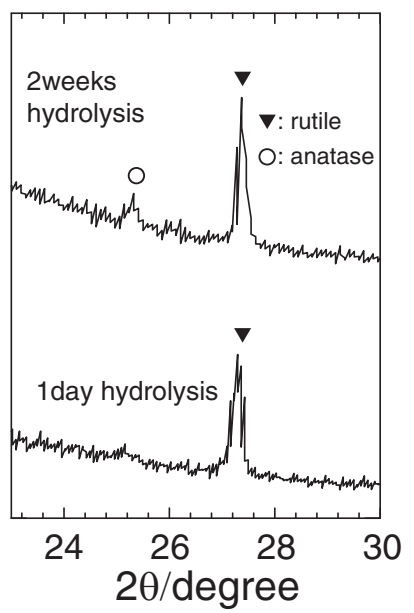

Fig. 6. Expanded XRD patterns of the $\mathrm{SiO}_{2}-\mathrm{TiO}_{2}$ fibers (Ti/Si: 0.078) with different hydrolysis periods.

\section{Summary}

Exposure of the silicone resin fiber to $\mathrm{TiCl}_{4}$ vapor indicates the trap of $\mathrm{TiCl}_{4}$ in the fiber as condensed phase. $\mathrm{TiCl}_{4}$ in the fiber is controllable by adjusting the curing time. Such cured fibers are effectively converted to $\mathrm{SiO}_{2}-\mathrm{TiO}_{2}$ fiber up to the $\mathrm{Ti} / \mathrm{Si}$ content of 0.078 . At the higher $\mathrm{TiCl}_{4}$ content, however, high gas pressure in the fiber during the pyrolysis forms long cracks along the fiber axis and the resulting $\mathrm{Ti} / \mathrm{Si}$ ratio decreases. The fiber surface is wholly covered by $\mathrm{TiO}_{2}$ particles in the size of $30-100 \mathrm{~nm}$, and larger grains in the size of $1-2 \mu \mathrm{m}$ are often observed. The obtained fiber reveals photocatalytic activity. The major phase is, however, rutile, and a large amount of $\mathrm{TiO}_{2}$ exists in the inner area of the fiber, which is difficult to be accessed by 2-propanol in the solution. Long time hydrolysis treatment of the fiber by ambient moisture promotes anatase formation at the fiber surface. Existence of anatase is, however, limited as compared with major rutile even under such condition.

Acknowledgements This work is partly supported by a Grantin Aid for Scientific Research C (No. 20560627) from the Japan Society of Promotion Science.

\section{References}

1) M. R. Hoffmann, S. T. Martin, W. Y. Choi and D. W. Bahnemann, Chem. Rev., 95, 69-96 (1995).

2) P. V. Kamat, Chem. Rev., 93, 267-300 (1993).

3) H. Yamashita, S. Kawasaki, Y. Ichihashi, M. Harada, M. Takeuchi, M. Anpo, G. Stewart, M. A. Fox, C. Louis and M. Che, J. Phys. Chem. B, 102, 5870-5875 (1998).

4) A. Fujishima, T. N. Rao and D. A. Tryk, J. Photochem. Photobiol. Chem., 1, 1-21 (2000).

5) S. Sampath, H. Uchida and H. Yoneyama, J. Catal., 149, 189194 (1994).

6) J. A. Byrne, B. R. Eggins, N. M. D. Brown, B. Mckinney and M. Rouse, Appl. Catal., B, 17, 25-36 (1998).

7) T. Tsumura, N. Kojitani, H. Umemura, M. Toyoda and M. Inagaki, Appl. Surf. Sci., 196, 429-436 (2002).

8) T. Ishikawa, H. Yamaoka, Y. Harada, T. Fujii and T. Nagasawa, Nature, 416, 64-67 (2002).

9) T. Ishikawa, Int. J. Appl. Ceram. Technol., 1, 49-55 (2004).

10) T. Matsunaga, H. Yamaoka, S. Ohtani, Y. Harada, T. Fujii and T. Ishikawa, Appl. Catal., A, 351, 231-238 (2008).

11) G. M. Renlund, S. Prochazka and R. H. Doremus, J. Mater. Res., 6, 2716-2722 (1991). 
12) F. I. Hurwitz, P. Heimann, S. C. Farmer and D. M. Hembree, Jr., J. Mater. Sci., 28, 6622-6630 (1993).

13) Y. W. Kim, S. H. Kim, C. M. Wang and C. B. Park, J. Am. Ceram. Soc., 86, 2231-2233 (2003).

14) M. Narisawa, R. Sumimoto, K. Kita, H. Kado, H. Mabuchi and Y. W. Kim, J. Appl. Polym. Sci., 114, 2600-2607 (2009).

15) M. Narisawa, Y. Satoh, R. Sumimoto, T. Kamegawa and Y. Yamashita, Mater. Sci. Forum, 658, 400-403 (2010).

16) H. Bockhorn, A. Hornung, U. Hornung, P. Jakobstroer and M.
Kraus, J. Anal. Appl. Pyrolysis, 49, 97-106 (1999).

17) H. Yamashita, M. Harada, J. Misaka, M. Takeuchi, K. Ikeue and M. Anpo, J. Photochem. Photobiol. Chem., 148, 257-261 (2002).

18) Y. Kuwahara, K. Maki, Y. Matsumura, T. Kamegawa, K. Mori and H. Yamashita, J. Phys. Chem. C, 113, 1552-1559 (2009).

19) Z. Ding, G. Q. Lu and P. F. Greenfield, J. Phys. Chem. B, 104, 4815-4820 (2000).

20) K. Y. Jung and S. B. Park, Appl. Catal., B, 25, 249-256 (2000). 